Abstracta Iranicacta Iranica

Revue bibliographique pour le domaine irano-aryen

Volume 40-41 | 2019

Comptes rendus des publications de 2017-2018

\title{
Nicholas Sims-Williams. An Ascetic Miscellany: The Christian Sogdian Manuscript E28
}

Florence Jullien

\section{Q OpenEdition \\ 12 Journals}

\section{Édition électronique}

URL : http://journals.openedition.org/abstractairanica/50892

DOI : 10.4000/abstractairanica.50892

ISBN : 1961-960X

ISSN : 1961-960X

Éditeur :

CNRS (UMR 7528 Mondes iraniens et indiens), Éditions de l'IFRI

Référence électronique

Florence Jullien, « Nicholas Sims-Williams. An Ascetic Miscellany: The Christian Sogdian Manuscript E28 », Abstracta Iranica [En ligne], Volume 40-41 | 2019, document 3, mis en ligne le 30 décembre 2019, consulté le 20 avril 2021. URL : http://journals.openedition.org/abstractairanica/50892 ; DOI : https:// doi.org/10.4000/abstractairanica.50892

Ce document a été généré automatiquement le 20 avril 2021.

Tous droits réservés 


\title{
Nicholas Sims-Williams. An Ascetic Miscellany: The Christian Sogdian Manuscript E28
}

\author{
Florence Jullien
}

\section{RÉFÉRENCE}

Nicholas Sims-Williams. An Ascetic Miscellany: The Christian Sogdian Manuscript E28.

(Berliner Turfāntexte XLII), Turnhout: Brepols Publishers, 2017, 396 p., 35 planches

d'illustrations N\&B. ISBN: 978-2-503-57878-1

1 Le manuscrit chrétien sogdien "E28" est constitué d'un ensemble de folios et de fragments de dimensions diverses actuellement conservés à Berlin, que N. SimsWilliams a rassemblés par commodité sous une unique appellation. Découverte dans l'oasis de Turfān, cette documentation provient du monastère de Bulayïq et constitue un important témoignage de l'implantation de l'Église syriaque-orientale en Asie centrale. Son contenu est de teneur ascétique, probablement de la main d'un seul scribe d'après l'A.

Dans une première partie (p. 9-71), sont réunis des extraits homilétiques, des commentaires et des sentences de trois maîtres spirituels de cette Églises, à la fois ascètes, théologiens et mystiques: Šem 'un d-Taybūteh, Isaac le Syrien et Dād-Ǐšóc Qațrāyā, qui vécurent tous trois à la fin du $7^{\mathrm{e}}$ siècle. Certains fragments avaient déjà été identifiés; d'autres ont pu l'être grâce aux travaux réalisés sur d'autres textes du corpus chrétien sogdien de Turfān; d'autres enfin sont inédits, comme par exemple le E28/8 qui conserve un commentaire de Dād-Ǐšō' sur le Paradis des Pères de 'Enan-Ǐšō'. L'A. fournit en apparat des parallèles comparatifs très utiles avec les versions syriaques qui nous sont restées de ces œuvres : parfois, le sogdien livre une lecture plus correcte que le syriaque. 
Dans une seconde partie (p. 73-87) sont présentées deux hagiographies fragmentaires : l'Histoire de Mār Awgin avec un extrait de l'Histoire de Milès rattachée à la précédente, et deux fragments indépendants du Martyre de Tarbō dans une version différente du syriaque (édité par P. Bedjan, Acta martyrum et sanctorum syriace II, Paris, 1891, p. 254-260).

4 Une dernière partie (p. 95-246) comprend une mosaïque de textes sur la vie ascétique, pour certains inédits, dont l'original fut probablement rédigé en syriaque. La plupart concerne l'acquisition des vertus propres à la vie spirituelle en contexte monastique.

Chaque fragment est présenté sur deux pages avec une traduction anglaise en regard de la transcription. Vient à la suite un commentaire philologique approfondi, avec parfois des références bibliques et patristiques; il tient compte de la bibliographie antérieure et fournit au besoin une brève histoire de la recherche, citant les publications afférentes aux extraits déjà identifiés ou (en partie) publiés (celles-ci également signalés en introduction).

6 Une édition de trois textes syriaques parallèles ou partiellement parallèles est livrée en appendice (p. *1-*20), sans traduction: l'Histoire de Mār Awgin, le Martyre de Tarbō et deux récits de l'Historia monachorum in Aegypto sur Abba Apellen. Le syriaque a été retranscrit par M. Dickens.

7 L'ouvrage s'achève par un glossaire (p. 247-317) des mots du corpus (certains reconstitués par l'A.), par un index verborum en sogdien et dans les langues utilisées (p. 333-337), une liste des abréviations (p. 319-322) ainsi qu'une bibliographie réduite (p. 323-332). 35 planches de photographies donnent un accès plus concret au matériau.

8 Les quelques petites maladresses de présentation ne nuisent cependant pas à la grande qualité de ce travail patient et extrêmement minutieux de reconstitution et d'identification qu'il faut saluer avec force. Comme tous les travaux de l'A. publiés dans cette collection, il s'agit d'une édition référente qui vient aussi apporter de nouvelles lectures et des précisions par rapport aux publications précédentes.

\section{AUTEURS}

\section{FLORENCE JULLIEN}

CNRS, Mondes iranien et indien, Paris 